\title{
SINTESIS DAN UJI TOKSISITAS SENYAWA ANALOG KALKON 3'- METOKSIASETOFENON DENGAN 2-HIDROKSIBENZALDEHID
}

\author{
David Aprianto ${ }^{1}$, Nur Balatif ${ }^{2}$, Adel Zamri ${ }^{3}$ \\ 1. Mahasiswa Program S1 Kimia FMIPA-Universitas Riau \\ 2,3. Dosen Jurusan Kimia FMIPA-Universitas Riau \\ Fakultas Matematika dan Ilmu Pengetahuan Alam Universitas Riau \\ Kampus Binawidya, Pekanbaru, 28293, Indonesia \\ E-mail: adel.zamri@lecturer.unri..ac.id
}

\begin{abstract}
ABSTRAK
Kalkon merupakan salah satu metabolit sekunder golongan flavonoid yang sangat berpotensi untuk dikembangkan. Kalkon telah dilaporkan memiliki aktivitas biologis seperti antimikroba, antitumor, antioksidan, antiinflamasi, antimalaria, dan antikanker. Senyawa (E)-3-(2-hidroksifenil)-1-(3'-metoksifenil)prop-2-en-1-on disintesis dengan metode iradiasi gelombang mikro dan menggunakan katalis basa $\mathrm{KOH}$. Struktur senyawa kalkon dikarakterisasi berdasarkan interpretasi data spektroskopi UV, IR, ${ }^{1} \mathrm{H}-\mathrm{NMR}$, dan MS. Uji toksisitas senyawa kalkon ditentukan

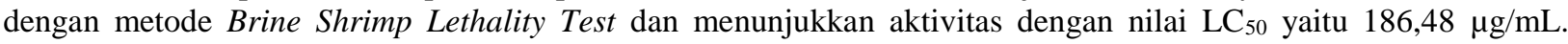
Senyawa ini menunjukkan aktivitas toksisitas yang baik karena nilai $\mathrm{LC}_{50}<200 \mu \mathrm{g} / \mathrm{mL}$.
\end{abstract}

Kata Kunci: Brine Shrimp Lethality Test, kalkon, sintesis

\section{PENDAHULUAN}

Senyawa kalkon merupakan senyawa metabolit sekunder golongan flavonoid yang sangat berpotensi untuk dikembangkan (Doan dan Tran, 2011). Senyawa kalkon telah banyak diaplikasikan di bidang farmasi dikarenakan kalkon memiliki aktivitas anestesi, antimikroba, antitumor, antiulser, antijamur, antikanker (Jayapal et al., 2010). Selain itu, kalkon juga dapat digunakan sebagai antioksidan, antimalaria, dan anti-inflamasi (Patil et al., 2009). Senyawa kalkon juga dikenal sebagai senyawa antara untuk mensintesis senyawa-senyawa heterosiklik, seperti flavon, flavanol, flavanon dan lain sebagainya yang juga mempunyai aktivitas biologis (Tiwari et al., 2010).

Aktivitas biologis kalkon, selain disebabkan oleh gugus karbonil $\alpha, \beta$ tak jenuh, juga dipengaruhi oleh subtituen yang terikat pada kedua cincin aromatiknya (Kamble et al., 2011). Senyawa kalkon yang mengandung gugus metoksi diindikasikan memiliki aktivitas sebagai toksisitas (Sari, 2014). Kalkon tidak hanya dapat disintesis menggunakan metode konvensional. Kalkon juga dapat disintesis menggunakan microwave. Apabila menggunakan microwave, pelarut dan katalis yang digunakan lebih sedikit sehingga ramah lingkungan dan mengimplementasikan green chemistry, waktu reaksi lebih cepat, produk yang dihasilkan lebih banyak, serta senyawa yang dihasilkan dapat lebih cepat murni (Mohan et al., 2010).

Pada penelitian ini bahan baku keton aromatik yang digunakan adalah 3'-metoksi asetofenon, dan sebagai aldehid aromatik adalah 2-hidroksibenzaldehid.

\section{METODOLOGI PENELITIAN}

\section{Alat dan Bahan}

Alat-alat yang digunakan dalam penelitian ini adalah microwave Samsung ME109F, alat pengukur titik leleh Fisher Johns (SMP 11Stuart ${ }^{\circledR}$ ), lampu UV 254/366 nm (Camag $\left.{ }^{\circledR}\right)$, HPLC (Shimadzu LC Solution jenis kolom Shimpack VP-ODS dengan panjang dan diameternya yaitu 150 x 4,6 mm), spektrofotometer UV (Genesys 10SUV-VIS v4.0022L9N175013), spektrofotometer FTIR (Shimadzu, IR Prestige21), spektroskopi ${ }^{1} \mathrm{H}-\mathrm{NMR}$ (Agilent $500 \mathrm{mHz}$ ), spektroskopi Massa (MS Waters LCT premier XE mode positif), peralatan sintesis dan uji toksisitas yang umum digunakan di Laboratorium Sintesis Organik.

Bahan-bahan yang digunakan dalam penelitian ini adalah 3-metoksiasetofenon (Merck), 2-hidroksibenzaldehida (Merck), kalium 
hidroksida, asam klorida, plat $\mathrm{KLT} \mathrm{GF}_{254}$, akuades, indikator universal, telur udang (Artemia salina Leach), air laut, etilasetat, nheksana, metanol, etanol absolut, kloroform dan dimetilsulfoksida (DMSO).

\section{Rancangan Penelitian}

Sintesis senyawa kalkon dilakukan dalam satu tahap reaksi melalui kondensasi ClaisenSchimdt dengan menggunakan senyawa awal 3metoksiasetofenon dan 2-hidroksibenzaldehid dengan katalis basa $(\mathrm{KOH})$ seperti terlihat pada skema reaksi berikut


Gambar 1. Sintesis senyawa kalkon

\section{Sintesis senyawa kalkon}

Sebanyak 5 mmol 3-metoksiasetofenon ditempatkan dalam wadah Erlenmeyer $125 \mathrm{~mL}$, kemudian ditambahkan 12,5 mL larutan alium hidroksida $6 \mathrm{~N}$. Setelah itu, sebanyak $5 \mathrm{mmol} 2-$ hidroksibenzaldehid dan $7,5 \mathrm{~mL}$ etanol absolut ditambahkan ke dalam Erlenmeyer. Campuran ini diiradiasi gelombang mikro selama 1-12 menit dengan daya 180 watt. Reaksi dipantau melalui uji KLT setiap 1 menit. Setelah itu, sebanyak 15 $\mathrm{mL}$ akuades dingin ditambahkan ke dalam campuran dan $\mathrm{pH}$ campuran dinetralkan dengan menambahkan asam klorida 3N. Kemudian campuran didiamkan. Endapan yang terbentuk disaring menggunakan pompa vakum dan dicuci dengan akuades dan n-heksana dingin, kemudian direkristalisasi dengan etanol. Produk yang diperoleh diuji kemurniannya dengan uji KLT, titik leleh dan analisis HPLC.

\section{Uji toksisitas dengan metode Brine Shrimp}

\section{Lethality Test (BSLT)}

Sampel sebanyak $20 \mathrm{mg}$ dilarutkan dalam 2 $\mathrm{mL}$ metanol (larutan induk, konsentrasi 10.000 $\mu \mathrm{g} / \mathrm{mL}$ ), kemudian dari larutan induk dibuat konsentrasi yang berbeda $1.000 \mu \mathrm{g} / \mathrm{mL}, 100$ $\mu \mathrm{g} / \mathrm{mL}, \quad 10 \mu \mathrm{g} / \mathrm{mL}$ dengan cara pengenceran bertingkat. Kemudian disiapkan vial $5 \mathrm{~mL}$ yang sudah dikalibrasi untuk masing-masing konsentrasi. Sampel dipipet ke dalam masingmasing vial sebanyak $0,5 \mathrm{~mL}$, lalu pelarut diuapkan hingga mengering. Selanjutnya, ke dalam masing-masing vial ditambahkan $50 \mu \mathrm{L}$ DMSO. Sebanyak 10 ekor larva udang dimasukkan ke dalam vial tersebut dan ditambah air laut hingga batas kalibrasi $5 \mathrm{~mL}$. Tingkat toksisitas diukur dengan cara menghitung jumlah larva udang yang masih hidup dalam selang waktu 24 jam. Pengujian dilakukan sebanyak tiga kali pengulangan dengan perlakuan yang sama untuk masing-masing konsentrasi. Data yang diperoleh dianalisis untuk menentukan nilai $\mathrm{LC}_{50}$ dengan metode kurva menggunakan tabel analisis probit.

\section{HASIL DAN PEMBAHASAN}

\section{Sintesis senyawa kalkon}

Penelitian ini mensintesis senyawa analog kalkon yang diperoleh dengan mereaksikan senyawa 3-metoksiasetofenon dan senyawa aldehid aromatik 2-hidroksi benzaldehid menggunakan katalis basa $\mathrm{KOH}$ dengan metode iradiasi gelombang mikro. Pelarut yang digunakan adalah etanol absolut karena lebih mudah didapatkan dan tingkat keracunannya lebih rendah dibandingkan pelarut organik lainnya. Selain itu, etanol absolut dapat membantu menyerap air hasil samping dari reaksi kimia yang terjadi.

Sintesis yang telah dilakukan menghasilkan senyawa kalkon dengan rumus molekul $\mathrm{C}_{16} \mathrm{H}_{14} \mathrm{O}_{3}$ dan berat molekul sebesar 255,1023. Senyawa kalkon berupa padatan berwarna merah dengan berat sebesar $1,1048 \mathrm{~g}$ dan rendemen yang dihasilkan sebesar 86,99\%. Sifat fisik dari senyawa kalkon yang dihasilkan dapat dilihat pada Tabel 1.

Tabel 1. Sifat fisika senyawa kalkon kalkon

\begin{tabular}{cccccc}
\hline Senyawa & Rumus molekul & Berat molekul & Warna & Rendemen $(\%)$ & Titik leleh $\left({ }^{\circ} \mathrm{C}\right)$ \\
\hline Kalkon & $\mathrm{C}_{16} \mathrm{H}_{14} \mathrm{O}_{3}$ & 255,1023 & Merah & 86,99 & $88-89$ \\
\hline
\end{tabular}


Analisis kemurnian senyawa kalkon dilakukan menggunakan KLT, titik leleh dan HPLC. Analisis kemurnian dengan KLT dilakukan menggunakan eluen yang bervariasi dan perbandingan yang berbeda. Senyawa kalkon menunjukkan satu noda pada plat KLT. Noda pada plat KLT diamati dengan bantuan lampu UV ( $\lambda 254 \mathrm{~nm}$ dan $366 \mathrm{~nm}$ ). Analisis kemurnian dengan titik leleh menunjukkan bahwa senyawa tersebut memiliki range titik leleh sebesar $1^{\circ} \mathrm{C}$. Analisis kemurnian senyawa kalkon menggunakan HPLC dilakukan pada panjang gelombang $250 \mathrm{~nm}$ dan $365 \mathrm{~nm}$ menunjukkan satu puncak dominan pada $t_{R}=15,26$ menit. Berdasarkan data analisis kemurnian tersebut menunjukkan bahwa senyawa kalkon telah murni.<smiles>COc1cccc(C(=O)/C=C/c2ccccc2O)c1</smiles>

Gambar 2. Struktur dan penomoran senyawa kalkon

Struktur senyawa kalkon yang telah murni dikarakterisasi menggunakan spektroskopi UV, FTIR, ${ }^{1} \mathrm{H}-\mathrm{NMR}$ dan MS. Spektrum UV senyawa kalkon memperlihatkan adanya serapan maksimum pada pada panjang gelombang 205 nm yang menunjukkan adanya ikatan rangkap pada cincin benzen, pada panjang gelombang 250 $\mathrm{nm}$ menunjukkan adanya resonansi dari cincin $\mathrm{A}$ aromatik hingga ke sistem karbonil dan pada panjang gelombang $350 \mathrm{~nm}$ menunjukkan adanya resonansi pada cincin $\mathrm{B}$ aromatic hingga ke sistem karbonil.

Spektrum FTIR senyawa kalkon memperlihatkan adanya serapan pada bilangan gelombang $3077,56 \mathrm{~cm}^{-1}$ yang menunjukkan adanya gugus $\mathrm{O}-\mathrm{H}$, pada bilangan gelombang $3011,98 \mathrm{~cm}^{-1}$ menunjukkan adanya gugus $\mathrm{C}-\mathrm{H}$ aromatik, pada bilangan gelombang $1675,25 \mathrm{~cm}^{-1}$ menunjukkan adanya gugus karbonil $\mathrm{C}=\mathrm{O}$, pada bilangan gelombang $1547,94 \mathrm{~cm}^{-1}$ menunjukkan adanya gugus metoksi $\mathrm{C}=\mathrm{C}$ alkena dan pada bilangan gelombang $1144,80 \mathrm{~cm}^{-1}$ menunjukkan adanya gugus $\mathrm{Ar}-\mathrm{OCH}_{3}$

Spektrum ${ }^{1} \mathrm{H}-\mathrm{NMR}$ senyawa kalkon menunjukkan bahwa jumlah proton dari senyawa tersebut sesuai dengan yang diharapkan, dapat dilihat pada Tabel 2.

Tabel 2. Spektrum ${ }^{1} \mathrm{H}-\mathrm{NMR}$ senyawa kalkon

\begin{tabular}{cc}
\hline $\begin{array}{c}\text { Nomor } \\
\text { Atom }\end{array}$ & $\begin{array}{c}\text { Senyawa }\left(\mathbf{D A} \mathbf{A}_{\mathbf{1}}\right) \\
\boldsymbol{\delta}_{\mathbf{H}}(\mathbf{p p m})\end{array}$ \\
\hline 1 & - \\
2 & $5,25(s, 1 \mathrm{H})(\mathrm{OH})$ \\
3 & $6,85(d, 1 \mathrm{H}, J=8 \mathrm{~Hz})$ \\
4 & $6,94(t, 1 \mathrm{H}, J=7,5 \mathrm{~Hz})$ \\
5 & $6,94(t, 1 \mathrm{H}, J=7,5 \mathrm{~Hz})$ \\
6 & $7,12(d, 1 \mathrm{H}, J=5 \mathrm{~Hz})$ \\
$\mathrm{C} \alpha$ & $7,35(d, 1 \mathrm{H}, J=16 \mathrm{~Hz})$ \\
$\mathrm{C} \beta$ & $8,12(d, 1 \mathrm{H}, J=16 \mathrm{~Hz})$ \\
$1^{\prime}$ & - \\
$2^{\prime}$ & $7,54(s, 1 \mathrm{H})$ \\
$3^{\prime}$, & $3,87(s, 3 \mathrm{H})(\mathrm{OCH})$ \\
$4^{\prime}$ & $7,19(d, 1 \mathrm{H}, J=7 \mathrm{~Hz})$ \\
$5^{\prime}$, & $7,59(t, 1 \mathrm{H}, J=7 \mathrm{~Hz})$ \\
6 & $7,12(d, 1 \mathrm{H}, J=5 \mathrm{~Hz})$ \\
\hline
\end{tabular}

Berat molekul kalkon ditunjukkan oleh spektrum massa yang dihitung sebagai $\mathrm{C}_{16} \mathrm{H}_{14} \mathrm{O}_{3}$

$\mathrm{M}+\mathrm{H}]^{+}$pada 255,1021 sedangkan yang ditemukan adalah 255,1023. Berdasarkan puncak ion molekul yang dihasilkan spektrum MS dan yang dihitung secara teoritis terlihat selisih nilai yang dihasilkan kecil. Hal ini menunjukkan senyawa hasil sintesis telah murni dan mempunyai struktur sesuai dengan yang diharapkan.

\section{Uji toksisitas}

Uji aktivitas toksisitas senyawa kalkon dilakukan dengan menggunakan metode Brine Shrimp Lethality Test (BSLT). Hasil uji toksisitas dari senyawa kalkon pada konsentrasi 1000, 100, dan $10 \mu \mathrm{g} / \mathrm{mL}$ terhadap larva Artemia salina Leach yang dianalisis dengan metode analisis probit tingkat potensi toksisitas senyawa kalkon dengan nilai $\mathrm{LC}_{50}$ sebesar $186,48 \mu \mathrm{g} / \mathrm{mL}$. Pada metode Brine Shrimp Lethality Test (BSLT), suatu tanaman atau hasil isolasi dianggap menunjukkan aktivitas sitotoksik bila mempunyai nilai $\mathrm{LC}_{50}$ kecil dari $1000 \mu \mathrm{g} / \mathrm{mL}$, sedangkan untuk senyawa murni dianggap menunjukkan aktivitas sitotoksik bila mempunyai nilai LC $_{50}$ 
kecil dari $200 \mu \mathrm{g} / \mathrm{mL}$ (Meyer, 1982). Berdasarkan hasil uji aktivitas toksisitas, senyawa kalkon positif berpotensi sebagai senyawa antikanker karena memiliki nilai $\mathrm{LC}_{50}<$ $200 \mu \mathrm{g} / \mathrm{mL}$.

\section{KESIMPULAN}

Berdasarkan hasil penelitian yang telah dilakukan, maka dapat diambil kesimpulan bahwa senyawa kalkon diperoleh melalui reaksi kondensasi aldol Claisen-Schmidt menggunakan katalis basa $(\mathrm{KOH})$ dibawah kondisi iradiasi microwave. Rendemen yang dihasilkan yaitu 86,99\%. Hasil karakterisasi menggunakan spektroskopi UV, FTIR, ${ }^{1} \mathrm{H}-\mathrm{NMR}$ dan MS menunjukkan bahwa senyawa yang diperoleh dari hasil penelitian adalah murni dan merupakan senyawa kalkon dengan struktur yang diharapkan. Senyawa kalkon memiliki toksisitas dengan nilai $\mathrm{LC}_{50}$ sebesar $186,48 \mu \mathrm{g} / \mathrm{mL}$, hasil tersebut menunjukkan bahwa senyawa kalkon positif berpotensi sebagai senyawa antikanker.

\section{DAFTAR PUSTAKA}

Doan, T.N., dan Tran, D.T. 2011. Synthesis, Antioxidant and Antimicrobial Activities of a Novel Series of Chalcones, Pyrazolic Chalcones, and Allylic Chalcones.Scientific Research. 2: 282-288.

Jayapal, M. R., Prasad, K. S., \& Sreedhar, N. Y. 2010. Synthesis and characterization of $4-$ hidroxy chalcones by aldol condensation using $\mathrm{SOCl}_{2} / \mathrm{EtOH}$. International Journal of Curent Pharmaceutical Research. 4(2): 60-62.
Kamble, V.M., Hatnapure, G.D., Keche, A.P., Birajdar, S., Patil, S.G., Tale, R.H., Rodge, A.H., Turkar, S.S. and Gour, K. 2011. Sintesis and Biological Evaluation of a Novel Series of Methoxylated Chalcones as Antioxidant and Anti-microbial agents. Journal. Chemistry. Pharmceutical. Research. 3(6):639-648.

Meyer, B.N.R., Ferrigni, J.E., Putnam, L.B., Jacosen, D.E., Nicholas, J.L and Laughin, M.C. 1982. Brine Shrimp: A Convenient General Bioassay for Active Plant Constituens . Journal of Medical Plant Medica. 45: 31-34.

Mohan, S.B., Behera, T.P., and Kumar, R. 2010. Microwave Irradiation Versus Conventional Method: Synthesis of Benzimidazolyl Chalcone Derivatives. International Journal of ChemTech Research. 2(3): 1634-1637.

Patil, C. B., Maharjan, S. K., \& Katti, S. A. 2009. Chalcone: A versatile molecule. Journal of Pharmaceutical Science and Research. 1(3): 11-12.

Sari, D.W.P. 2014. Sintesis dan Uji Toksisitas Senyawa Analog Kalkon Turunan 3',4'Dimetoksi asetofenon. Jurnal Online Mahasiswa FMIPA. 1(2): 100-104.

Tiwari, B., Pratapwwar, A. S., Tapas, A. R., Butle, S. R., \& Vatkar, B. S. 2010. Synthesis and Antimicrobial activity of some chalcone derivates. International Journal of ChemTech Research. 1(2): 499503. 